\title{
RESEARCH
}

Open Access

\section{The plasma peptidome}

Jaimie Dufresne', Pete Bowden', Thanusi Thavarajah', Angelique Florentinus-Mefailoski', Zhuo Zhen Chen', Monika Tucholska', Tenzin Norzin'1, Margaret Truc Ho ${ }^{1}$, Morla Phan' ${ }^{1}$ Nargiz Mohamed', Amir Ravandi², Eric Stanton ${ }^{3}$, Arthur S. Slutsky ${ }^{4}$, Claudia C. dos Santos ${ }^{5}$, Alexander Romaschin', John C. Marshall, Christina Addison ${ }^{6}$, Shawn Malone ${ }^{6}$, Daren Heyland ${ }^{7}$, Philip Scheltens ${ }^{8}$, Joep Killestein ${ }^{9}$, Charlotte Teunissen ${ }^{10}$, Eleftherios P. Diamandis ${ }^{11}$, K. W. M. Siu ${ }^{12}$ and John G. Marshall ${ }^{1,13^{*}}$ (])

\begin{abstract}
Background: It may be possible to discover new diagnostic or therapeutic peptides or proteins from blood plasma using LC-ESI-MS/MS to identify, quantify and compare the statistical distributions of peptides cleaved ex vivo from plasma samples from different clinical populations.
\end{abstract}

Methods: A systematic method for the organic fractionation of plasma peptides was applied to identify and quantify the endogenous tryptic peptides from human plasma from multiple institutions by C18 HPLC followed nano electrospray ionization and tandem mass spectrometry (LC-ESI-MS/MS) with a linear quadrupole ion trap. The endogenous tryptic peptides, or tryptic phospho peptides (i.e. without exogenous digestion), were extracted in a mixture of organic solvent and water, dried and collected by preparative C18. The tryptic peptides from 6 institutions with 12 different disease and normal EDTA plasma populations, alongside ice cold controls for pre-analytical variation, were characterized by mass spectrometry. Each patient plasma was precipitated in $90 \%$ acetonitrile and the endogenous tryptic peptides extracted by a stepwise gradient of increasing water and then formic acid resulting in 10 sub-fractions. The fractionated peptides were manually collected over preparative C18 and injected for 1508 LC-ESI-MS/MS experiments analyzed in SQL Server R.

Results: Peptides that were cleaved in human plasma by a tryptic activity ex vivo provided convenient and sensitive access to most human proteins in plasma that show differences in the frequency or intensity of proteins observed across populations that may have clinical significance. Combination of step wise organic extraction of $200 \mu \mathrm{L}$ of plasma with nano electrospray resulted in the confident identification and quantification $\sim 14,000$ gene symbols by X!TANDEM that is the largest number of blood proteins identified to date and shows that you can monitor the ex vivo proteolysis of most human proteins, including interleukins, from blood. A total of 15,968,550 MS/MS spectra $\geq$ E4 intensity counts were correlated by the SEQUEST and X!TANDEM algorithms to a federated library of 157,478 protein sequences that were filtered for best charge state $(2+$ or $3+)$ and peptide sequence in SQL Server resulting in 1,916,672 distinct best-fit peptide correlations for analysis with the $\mathrm{R}$ statistical system. SEQUEST identified some 140,054 protein accessions, or some $\sim 26,000$ gene symbols, proteins or loci, with at least 5 independent correlations. The X!TANDEM algorithm made at least 5 best fit correlations to more than 14,000 protein gene symbols with p-values and FDR corrected q-values of $\sim 0.001$ or less. $\log _{10}$ peptide intensity values showed a Gaussian distribution from E8 to E4 arbitrary counts by quantile plot, and significant variation in average precursor intensity across the disease and controls treatments by ANOVA with means compared by the Tukey-Kramer test. STRING analysis of the

\footnotetext{
*Correspondence: 4marshal@ryerson.ca

${ }^{1}$ Ryerson Analytical Biochemistry Laboratory (RABL), Department of Chemistry and Biology, Faculty of Science, Ryerson University, 350 Victoria St, Toronto, ON, Canada

Full list of author information is available at the end of the article
} 
top 2000 gene symbols showed a tight association of cellular proteins that were apparently present in the plasma as protein complexes with related cellular components, molecular functions and biological processes.

Conclusions: The random and independent sampling of pre-fractionated blood peptides by LC-ESI-MS/MS with SQL Server-R analysis revealed the largest plasma proteome to date and was a practical method to quantify and compare the frequency or $\log _{10}$ intensity of individual proteins cleaved ex vivo across populations of plasma samples from multiple clinical locations to discover treatment-specific variation using classical statistics suitable for clinical science. It was possible to identify and quantify nearly all human proteins from EDTA plasma and compare the results of thousands of LC-ESI-MS/MS experiments from multiple clinical populations using standard database methods in SQL Server and classical statistical strategies in the R data analysis system.

Keywords: Endogenous tryptic peptides phospho peptides, Human EDTA plasma, Organic extraction, Nano chromatography, Electrospray ionization tandem mass spectrometry, LC-ESI-MS/MS, Linear quadrupole ion trap

\section{Introduction}

In theory all tissues and cells are in constant communication via endo/exocytosis or secretion with the extracellular space that is directly or indirectly contiguous with the circulatory systems and thus the blood fluids $[1,2]$. Tryptic peptides analyzed by high pressure liquid chromatography (HPLC) [3] with electrospray ionization [4] followed by ion trap MS/MS fragmentation (LCESI-MS/MS) have been shown to reliably identify and quantify peptides from Eukaryotic samples [5-7]. Only a few hundred blood proteins may be detected by preparative 1D poly acrylamide gel electrophoresis (PAGE) [8] or analytical 2D PAGE [9]. A direct comparison of electrophoresis followed by LC-ESI-MS/MS compared to partition chromatography followed by LC-ESI-MS/ MS showed that direct chromatographic methods had much greater sensitivity [8]. Plasma or serum proteins may be digested with trypsin and identified by fitting the MS/MS spectra to non-tryptic peptides [10-13]. Exogenous tryptic digestion of blood fluids results in the highly redundant analysis of albumin, apolipoproteins, immunoglobulins $[14,15]$, and other well-known blood proteins $[1,2]$. In contrast, examination of endogenous peptides shows a greater representation of apparently cellular proteins $[16,17]$. The agreement on the identified proteins of human blood fluids from MS/MS spectra between "Fully Tryptic" peptides that are constrained to end in $\mathrm{R}$ or $\mathrm{K}[8,15]$ versus the "No Enzyme" peptides that are free to end with any of the 20 amino acids [10, 11 is powerful evidence for the veracity of LC-ESI-MS/ MS of tryptic peptides [14, 18, 19]. The statistical sufficiency of MS/MS correlation with an ion trap has been confirmed by independent experimental methods including computing MS/MS to peptide $\mathrm{p}$-values (and FDR q-values), or comparison to noise MS/MS and random MS/MS simulations $[20,21]$ and is in agreement with the results from 300,000 synthetic test peptides [22] or pure viral cultures [23]. Blood fluid contains a weak tryptic activity [24] that apparently may cleave endogenous peptides in vivo (peptidome) but endogenous proteolytic activities may also generate high levels of some of these same peptides ex vivo (degradome) $[25,26]$ since these two pools show some overlap [27]. Incubation of plasma at room temperature seemed to result in an apparent steady state where peptides are being created by endoproteinases and degraded by exopeptidases [27-29]. To date the isolation and identification of the endogenous peptides from human plasma has seemed technically challenging [30]. The most abundant endogenous peptides of human blood fluid were first identified by $\mathrm{C} 18$ partition chromatography followed by MALDI-MS/MS with a Qq-TOF or LC-ESI-MS/MS with an ion trap, tandem mass spectrometer $[8,28]$. The problem of low signal strength from blood peptides was first addressed by examining haemofiltrate [31] and/or the use of sensitive MALDI analysis [32, 33]. The use of precipitation and selective extraction of the protein pellet was shown to be superior to precipitation and analysis of the ACN supernatant [34], ultra-filtration, [11] albumin depletion chromatography [35], partition chromatography (DEAE ion exchange \& C18) or C18 alone [8]. Organic extraction may have some advantage to detect cellular proteins compared to the redundant identification of canonical circulating proteins frequently observed from depletion chromatography [10], ultrafiltration [11], or partition chromatography $[8,15]$ of blood proteins followed by trypsin digestion. Precipitating the blood peptides for organic/water extraction has resulted in the identification of cellular proteins and regulatory molecules and growth factors $[16,17,36,37]$. It will be necessary to identify, quantify and compute the statistical distributions of the endogenous tryptic peptides cleaved from the proteins ex vivo in blood plasma compared to ice cold controls to understand and compare treatment versus pre-analytical variation in different clinical populations and controls.

Precipitation of the sample with nine volumes of acetonitrile results in a pellet that contains almost all the peptides and proteins that may be selectively extracted 
from the insoluble pellet by a stepwise gradient of acetonitrile/water for collection over C18 followed by LCESI-MS/MS that provides high signal-to-noise ratios [38] and combined with nanospray resulted in the identification of cellular proteins and regulatory molecules such as interleukins and growth factors. Here the proteins in blood that were cleaved in human plasma ex vivo provided convenient and sensitive access to almost all human proteins and classical statistical approaches detected variation between clinical populations, female samples and ice cold degradation controls.

\section{Materials and methods Materials}

The HPLC was an Agilent 1100 (Santa Clara CA USA). The linear ion trap mass spectrometer was a LTQ XL (Thermo Electron Corporation, Waltham, MA, USA). Anonymous human EDTA plasma with no identifying information was obtained from the multiple clinical locations of St Joseph's Hospital of McMaster University, the Ontario Tumor Bank of the Ontario Institute of Cancer Research, St Michaels Hospital Toronto, Amsterdam University Medical Centers, Vrije Universiteit Amsterdam, and IBBL Luxembourg under Ryerson Ethic Review Board Protocol REB 2015-207. The arbitrarily-selected disease population samples were from patients that received a confirmed diagnoses of the disease indicated at the source institution. The plasma samples were collected before therapeutic intervention and no additional information about the samples were made available. C18 ZipTips were obtained from Millipore (Bedford, MA). C18 HPLC resin was from Agilent (Zorbax 300 SB-C18 5-micron). Solvents were obtained from Caledon Laboratories (Georgetown, Ontario, Canada). All other salts and reagents were obtained from Sigma-Aldrich-Fluka (St Louis, MO) except where indicated.

\section{Sample preparation}

The samples stored at $-80{ }^{\circ} \mathrm{C}$ were thawed on ice and briefly vortexed before pipetting $200 \mu \mathrm{L}$ in the bottom of a $2 \mathrm{ml}$ sample tube on ice. The endogenous tryptic peptides or tryptic phospho peptides (i.e. without exogenous digestion) were extracted in a step gradient of organic solvents, dried and collected by preparative $\mathrm{C} 18$ [38]. Disposable plastic $2.0 \mathrm{ml}$ sample tubes and plastic pipette tips were used to handle samples. The $200 \mu \mathrm{l}$ of EDTA plasma samples were precipitated with $90 \%$ acetonitrile [34], that contains few peptides, followed by the selective extraction of the pellet using a step gradient to achieve selectivity across sub-fractions and thus greater sensitivity [38]. Human EDTA plasma samples $(200 \mu \mathrm{l})$ were precipitated with 9 volumes $(1800 \mu \mathrm{L})$ of $100 \%$ acetonitrile (final $90 \% \mathrm{v} / \mathrm{v}$ ). First, the acetonitrile suspension was separated with a centrifuge at 14,000 RCF for $5 \mathrm{~min}$. Next, the acetonitrile supernatant was collected, transferred to a fresh sample tube and freeze dried in a rotary lyophilizer. The organic precipitate (pellet) that contains a much larger total amount of endogenous polypeptides $[17,36]$ was manually re-suspended in a $200 \mu \mathrm{L}$ volume using a step gradient of increasing water content to yield 10 fractions from the most organic soluble $90 \%$ ACN supernatant to $10 \% \mathrm{ACN}$, followed by $100 \% \mathrm{H}_{2} \mathrm{O}$, and then 5\% formic acid [38]. At each step the extract was clarified with a centrifuge at 14,000 RCF for $5 \mathrm{~min}$. Supernatant from each step fraction was dried under vacuum in a rotary lyophillizer and stored at $-80{ }^{\circ} \mathrm{C}$ for analysis.

\section{Preparative micro $\mathrm{C} 18$ chromatography}

Extracted peptides of EDTA plasma were then re-dissolved in 5\% formic acid for preparative C18 chromatography $(0.5 \mu \mathrm{L}$ ZipTip). Solid phase extraction with C18 for LC-ESI-MS/MS were performed as previously described $[8,15,28,36,37]$. The C18 chromatography resin (zip tip) was wet with $65 \%$ acetonitrile before equilibration in water with $5 \%$ acetonitrile and $5 \%$ formic acid. The plasma extract was dissolved in $200 \mu \mathrm{L}$ of $5 \%$ formic acid in water. The resin was washed with at least five volumes of the same binding buffer. The resin was eluted with $2 \mu \mathrm{L}$ of $65 \%$ acetonitrile in $5 \%$ formic acid. The preparative resin was discarded after a single use.

\section{LC-ESI-MS/MS}

Disease and matched normal control sample fraction sets were replicated in blocks over each of five LTQ XL Linear Quadrupole ion traps that were cleaned and tested between patients. The linear quadrupole ion traps were tested for sensitivity by infusion with Glu Fib and angiotensin II. To entirely prevent any possibility of cross contamination between patient step-fraction sets, a new analytical column and emitter tip was fabricated for each patient. Sensitivity and accuracy of the LC-ESI-MS/ MS was tested using a mixture of cytochrome c, glycogen phosphorylase $\mathrm{B}$ and alcohol dehydrogenase [20, $21,27,39,40]$ prior to recording the peptides from each patient sub-fraction set. Stepwise extractions were collected and desalted over C18 preparative micro columns, eluted in $2 \mu \mathrm{L}$ of $65 \% \mathrm{ACN}$ and $5 \%$ formic acid, and then were diluted tenfold with $0.1 \%$ formic acid in water before loading into a $20 \mu \mathrm{L}$ metal sample loop with manual injection onto the analytical column via a Rhodynne injector. Endogenous peptide samples were analyzed over a discontinuous gradient generated at a flow rate of $\sim 10$ microlitres per minute split upstream of the injector during recording to about $\sim 200 \mathrm{nl}$ per minute. Separation was performed with a $\mathrm{C} 18(150 \mathrm{~mm} \times 0.15 \mathrm{~mm})$ fritted 
capillary column. Acetonitrile profile was at 5\% during injection, was ramped to $12 \%$ after $5 \mathrm{~min}$ and then increased to $65 \%$ over $\sim 60 \mathrm{~min}$, remained at $65 \%$ for $5 \mathrm{~min}$, decreased to $50 \%$ for $15 \mathrm{~min}$ and then declined to a final proportion of $5 \%$ prior to injection of the next step fraction from the same patient. Nano HPLC effluent was analyzed by nanospray ionization with detection by MS and fragmentation by MS/MS with a linear quadrupole ion trap [41]. The instrument was set to collect the precursor for up to 200 milli seconds prior to MS/MS fragmentation with up to four fragmentations per precursor ion that were combined. On average, about 10 independent patient plasma samples from each of 13 distinct sample sets with control versus disease treatments from multiple institutions or studies (McMaster, St Michael's Hospital, Hospital Zentraal, Ontario Tumor Bank, and IBBL) were precipitated, fractionated over a step gradient and collected over $\mathrm{C} 18$ for manual injection. In the case of heart attack where low variation was observed, greater sampling density was employed.

\section{Sampling and analysis strategy}

Endogenous tryptic peptides extracted from the disease and/or matched control treatments (ovarian cancer, breast cancer, sepsis, Alzheimer's dementia, multiple sclerosis and heart attack) and ice cold plasma controls were randomly and independently sampled by LC-ESIMS/MS [27] (13 treatments with 1508 successful LCESI-MS/MS experiments). Independent patient samples from the each of the disease and normal treatments were separated into 10 sub-fractions that were randomly and independently sampled by the linear quadrupole ion trap that provided the precursor ion $\mathrm{m} / \mathrm{z}$ and intensity values. Disease and matching control sample fraction sets were replicated in blocks over each of five identical LTQ XL Linear Quadrupole ion traps. Accession numbers, actual and estimated masses $[\mathrm{M}+\mathrm{H}]^{+}$, correlated peptide sequences, peptide and protein scores, resulting protein sequences and other associated data were captured and assembled together in an SQL Server relational database for analysis with the R generic statistical analysis system [18].

\section{Correlation analysis}

Correlation analysis of ion trap data was performed with X!TANDEM [42] and SEQUEST [6] algorithms to match tandem mass spectra to peptide sequences from the Homo sapiens RIKEN, IMAGE, RefSeq, ENSEMBL, UNIPROT, UNIPARC and SwissProt Federated Library of 157,478 protein sequences that differ by at least one amino acid. Correlation algorithms may match one MS/MS spectra to more than one peptide sequence, or charge state, or to the same peptide found in many proteins, that can be filtered using SQL Server database system to avoid redundant correlations and over interpretation of the data [15, 27, 39, 40, 43]. Endogenous peptides were searched as fully tryptic peptides on separate servers for the SEQUEST and X!TANDEM algorithms and these results were combined in an SQL Server relational database. The ion trap data was analyzed within $\pm 3 \mathrm{~m} / \mathrm{z}$ from fully tryptic precursor peptides considered from 300 to $2000 \mathrm{~m} / \mathrm{z}$ with a tolerance of $0.5 \mathrm{Da}$ error in the fragments with up to three missed cleavages [42]. The entire correlation procedure for fully tryptic peptides was repeated with the additional consideration of phosphate on serine, threonine or tyrosine residues as specified in the X!TANDEM and SEQUEST software algorithms: The precursor intensity and frequency counts from the 13 plasma treatments $\times 2$ independent correlations (tryptic and phospho tryptic) resulted in 26 treatments for statistical analysis.

\section{Data sorting, transformation and visualization}

The peptide identity and $[\mathrm{M}+\mathrm{H}]^{+}$were computed from the MS/MS spectra by the SEQUEST and X!TANDEM algorithms. The X!TANDEM and SEQUEST correlation algorithms can automatically match one MS/MS spectra to more than one peptide sequence or charge state that may be subsequently filtered out using the SQL Server database system to avoid redundant correlations $[15,27,39,40,43]$. Only the single best fit (Rank 1) peptide from the MS/MS at charge states of +2 versus +3 were accepted with additional acetylation or oxidation of methionine and with possible loss of water or ammonia. The results from the LC-ESI-MS/MS spectra together with the results of the correlation algorithms were parsed into an SQL Server that was analyzed by the open source $\mathrm{R}$ statistical analysis system [14, 18, 39, 40, 44]. A continuous variable (such as $\log _{10}$ intensity) that is randomly and independently sampled across multiple clinical sites and treatments, and that is linear and Gaussian by quantile plot, is an ideal candidate for means comparison by ANOVA followed by Tukey-Kramer Honestly significant differences test, a classical statistical analysis used in clinical research, basic research, engineering and agricultural science $[27,28,39,40,44,45]$. The charts, tables and statistical tests for the 1.9 million filtered data points were created using the library Rcmdr in R. The MS/MS correlations $\mathrm{p}$-values and intensity values of the fully tryptic and/or phospho tryptic peptides were computed per gene symbol using the SQL SERVER/R data system. The intensity data was $\log _{10}$ transformed, tested for normality and analyzed by means, standard errors and ANOVA with the R statistical analysis system. 
Table 1 The number of $m$ gf files with MS/MS spectra >E4 counts search against the human proteins by X!TANDEM and SEQUEST

\begin{tabular}{|c|c|c|}
\hline Treatment ID\# & MGF file count & TreatmentName \\
\hline 1 & 115 & Alzheimer control \\
\hline 2 & 115 & AlzHeimer control STYP \\
\hline 3 & 120 & AlzHeimer \\
\hline 4 & 120 & Alzheimer STYP \\
\hline 5 & 89 & Cancer breast \\
\hline 6 & 89 & Cancer breast STYP \\
\hline 7 & 50 & Cancer control \\
\hline 8 & 50 & Cancer control STYP \\
\hline 9 & 90 & Cancer ovarian \\
\hline 10 & 90 & Cancer ovarian STYP \\
\hline 11 & 12 & Ice cold control \\
\hline 12 & 12 & Ice cold control STYP \\
\hline 13 & 211 & Heart attack arterial \\
\hline 14 & 211 & Heart attack arterial STYP \\
\hline 15 & 267 & Heart attack venous control \\
\hline 16 & 267 & $\begin{array}{l}\text { Heart attack venous control } \\
\text { STYP }\end{array}$ \\
\hline 17 & 121 & Heart attack venous \\
\hline 18 & 121 & Heart attack venous STYP \\
\hline 19 & 121 & Multiple sclerosis control \\
\hline 20 & 121 & Multiple sclerosis control STYP \\
\hline 21 & 122 & Multiple sclerosis \\
\hline 22 & 122 & Multiple sclerosis STYP \\
\hline 23 & 100 & Sepsis \\
\hline 24 & 100 & Sepsis STYP \\
\hline 25 & 90 & Sepsis control \\
\hline 26 & 90 & Sepsis control STYP \\
\hline LCMS runs searched & 1508 & Fully Tryptic \\
\hline LCMS runs searched & 1508 & Phospho Tryptic STYP \\
\hline
\end{tabular}

A total of 1508 mgf files with high intensity spectra greater than E4 counts were searched both as fully tryptic and phospho tryptic peptides and the results compared as separate treatments

\section{Results}

The number of sample fractions that showed intense LC-ESI-MS/MS spectra > E4 counts seemed to vary between treatments and it was more difficult to detect peptides from control plasma collected on ice compared to the clinical samples (Table 1). Fully tryptic peptides and/or phospho peptides from $\sim 14,000$ gene symbols (X!TANDEM) or nearly all 26,000 gene symbols (SEQUEST) of the known human proteins were observed by a progressive stepwise extraction of the organic protein pellet of human EDTA plasma. The stepwise extraction apparently revealed peptides from many cellular proteins and regulatory proteins such as growth factors, cytokines, chemokines, necrosis factors and interleukins in circulation and provided a comprehensive analysis of the endogenous tryptic peptides in human plasma. (Additional file 1: Table S1; Additional file 2: Table S2). The analysis of the endogenous peptides by nano-electrospray ionization with a linear quadrupole ion trap showed highly significant protein $\mathrm{p}$-values and FDR-corrected q-values from the best fit of MS/MS spectra to tryptic peptides.

\section{LC-ESI-MS/MS}

The pool of endogenous tryptic peptides (TRYP) and/ or phosphopeptides (TRYP-STYP) were extracted in organic solvent/water for collection over C18 [46, 47] and analyzed by random and independent sampling from independently replicated disease and normal samples without replacement by analytical C18 LC-ESI-MS/ MS (Table 1). The MS/MS spectra were correlated to the tryptic peptides of the federated library of human proteins by the SEQUEST and X!TANDEM algorithms. Some 15,043,678 MS/MS spectra from precursor ions of typically greater than 10,000 arbitrary intensity counts from 1508 nano spray LC-ESI-MS/MS runs were recorded (Table 2).

\section{SQL analysis of MS/MS spectra to peptides and proteins} A total of $94,483,230$ redundant MS/MS spectra to peptide matches (precursor intensity $\geq \mathrm{E} 4$ counts) to the library of 157,478 proteins from a total of $19,197,152$

Table 2 The filtering of proteins from endogenous tryptic peptides (TRYP) or tryptic phospho peptides (STYP) from the stepwise extraction of human EDTA plasma with a mixture of organic solvent and water where MS/ MS correlations from precursor ions of greater than E4 $(10,000)$ arbitrary counts were accepted from 1508 LCESI-MS/MS runs

\begin{tabular}{ll}
\hline MS/MS spectra & $15,968,550$ \\
Protein filtering & \\
Protein library & 157,478 \\
Correlations & $94,483,230$ \\
Best charge state (Filter 1) & \\
Protein accessions & 156,280 \\
Correlations & $19,889,758$ \\
Best charge state and peptide sequence (Filter 2) & \\
Protein accessions & 156,279 \\
Correlations & $19,197,152$ \\
Rank 1 Peptides & \\
Peptide identification count & $19,197,152$ \\
Distinct peptide identification count & $4,631,474$ \\
Distinct peptide sequence count & $1,916,672$ \\
Peptides from $\geq 3$ correlations per protein & 486,895 \\
\hline
\end{tabular}

About $12 \%$ of MS/MS spectra from precursors greater than E4 counts were accepted as the best fit to a fully tryptic peptide or phosphopeptide 
correlations to 156, 279 different protein accessions collapsed in the SQL Server to 1,916,672 distinct, Rank 1 correlations to 26,251 possible gene symbols (Table 2).

\section{Identification of peptides by SEQUEST and X!TANDEM}

The SEQUEST algorithm was very sensitive and tryptic peptides and/or phosphopeptides from immunoglobulin molecules were detected as many as ten thousand times with some 4 " E5 peptides correlated at least 3 times (Fig. 1a). The SEQUEST results showed a bias toward identifying peptides from large proteins such as titin, nebulin, spectrin, obscurin, microtubule cross linking factor, ANAK, and others that result from noise or misscorrelation [20, 21, 48]. In contrast, X!TANDEM detected about $1.5 *$ E5 tryptic and phospho peptides at least 3 times (Fig. 1b). Combining the results of SEQUEST and X!TANDEM showed a total of about 140,000 protein accessions (Fig. 2a) and about 24,000 gene symbols (Fig. 2b) that were identified at least 5 times. Thus nearly every human gene symbol was provisionally identified by LC-ESI-MS/MS from organic extraction of plasma by the heuristic SEQUEST algorithm that does not provide a direct measure of confidence with respect to random expectation.

\section{Statistical distributions of individual peptides from X!TANDEM}

The X!TANDEM algorithm generates a p-value that the experimental MS/MS matched the predicted spectra of a peptide in the human protein library and so it was possible to compute the probability distributions for peptides, protein accessions and gene symbols. X!TANDEM matched 1,135,806 MS/MS spectra to peptide sequences (Fig. 3). The peptide intensity values ranged from E8 to E4 counts that is over 4 orders of magnitude, approximated a normal distribution, and the variation in precursor intensity values was well-explained over peptides by ANOVA $(\mathrm{p} \leq \mathrm{E}-15)$ (Fig. 3a). The $[\mathrm{M}+\mathrm{H}]^{+}$values ranged from about 900 to $5000 \mathrm{Da}$, and approximated a normal distribution (Fig. 3b). The peptide delta mass values were linear from from -2 to $+4 \mathrm{Da}$ and showed a close fit to a Gaussian distribution (Fig. 3c). The precursor intensity had little effect on the peptide p-values that ranged from E-1 to E-15 (Fig. 3d). The scatter plot of peptide intensity versus $[\mathrm{M}+\mathrm{H}]^{+}$showed an increasing trend ( $\mathrm{p}$-value: $\leq 2.2 \mathrm{e}-16)$ consistent with greater momentum on detector impact (Fig. 3e). There was a Gaussian relationship between $\log$ p-values and delta mass (Fig. 3f). The individual peptide p-values ranged from E-1 to E-14 (Fig. 3g). The most significant peptide p-values ranged from 1000 to $4000 \mathrm{Da}$ (Fig. 3h). The peptide p-values did not closely approximate a normal or Gaussian curve in the outer quantiles (Fig. 3i).

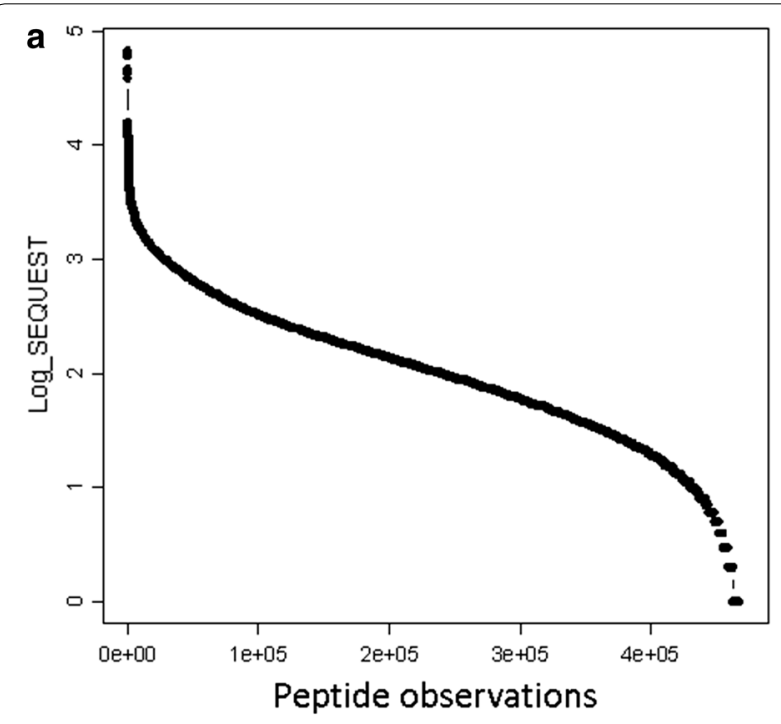

b

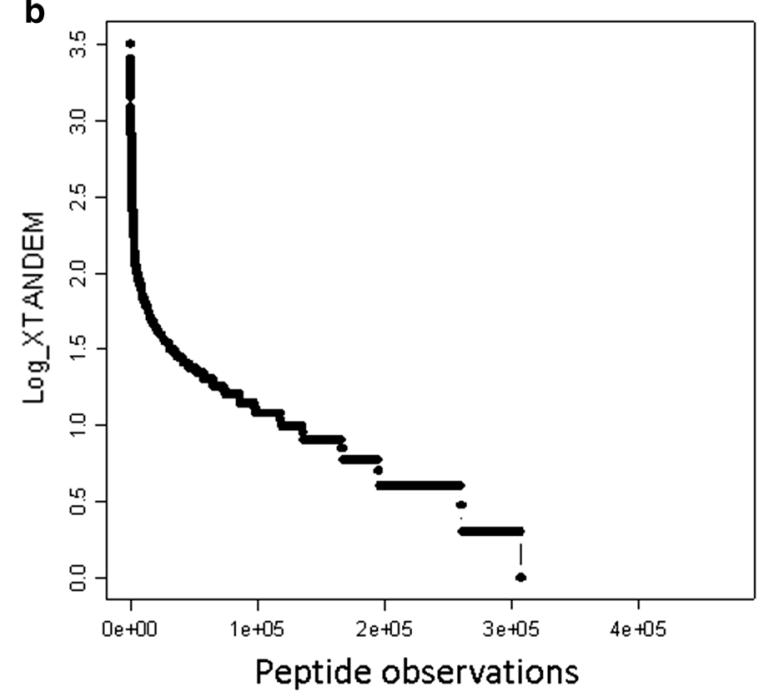

Fig. 1 The human endogenous tryptic peptides and/or phosphopeptides where precursor intensity is greater than E4 $(10,000)$ arbitrary detector counts after selecting the best fit of MS/ MS spectra from 2+ or 3+ ions and selecting the single best peptide fit for each MS/MS fragmentation spectrum (Filter 2). a the SEQUEST algorithm; $\mathbf{b}$ the X!TANDEM algorithm

\section{Computation of X!TANDEM results per protein accession}

The X!TANDEM algorithm computed at least three correlations to $\sim 40,000$ protein accessions (Fig. 4a). The average p-values of the observed peptide sequences ranged from E-1 to E-5 (Fig. 4b, c). The average intensity values significantly varied over protein accessions (ANOVA $\mathrm{p} \leq \mathrm{E}-15)$ that ranged from E8 to E4 arbitrary counts (Fig. 4d). The standard error of the peptide intensity was typically less than $0.5 \log _{10}$ units (Fig. 4e). The cumulative $\mathrm{p}$-values at the level of the protein accession that ranged 

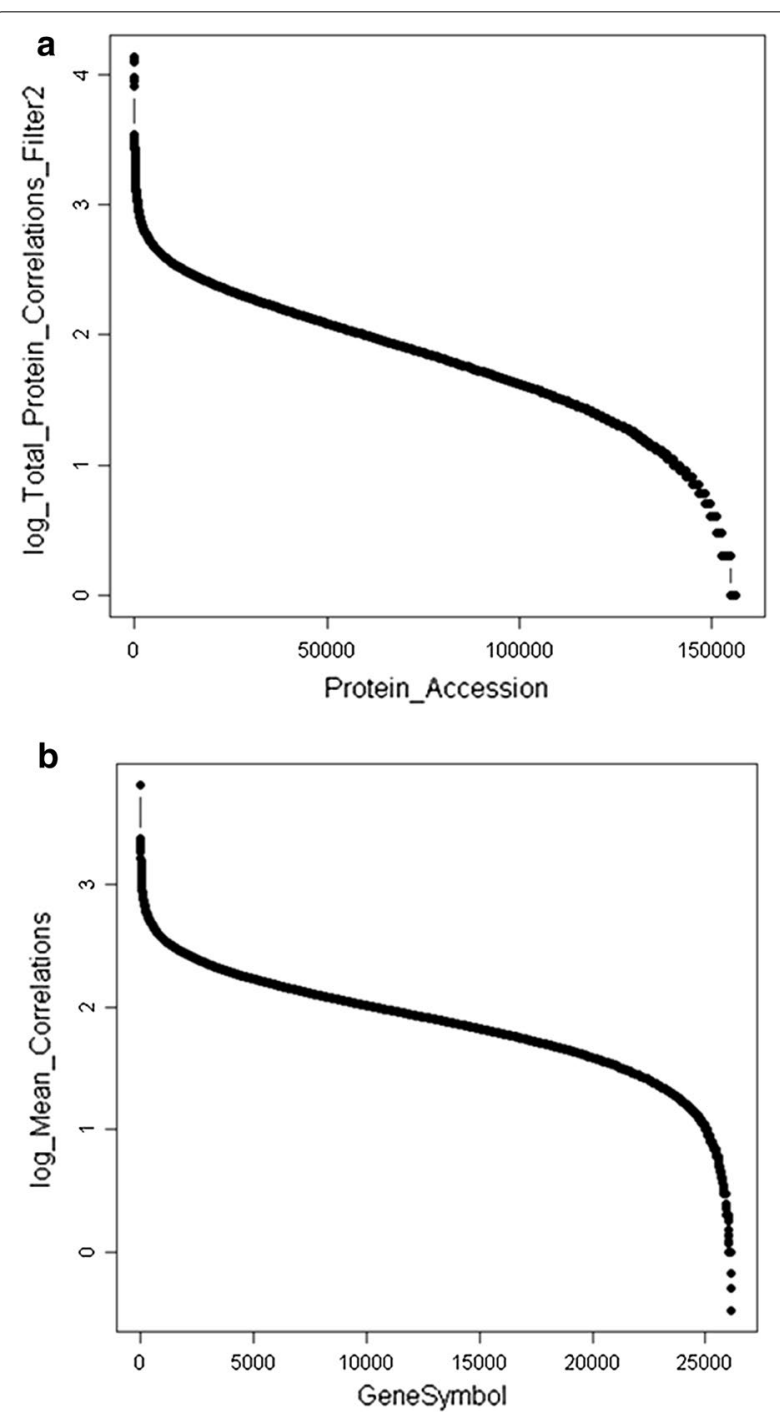

Fig. 2 The human protein gene symbols identified by endogenous tryptic peptides and/or phosphopeptides using Filter 2 where precursor intensity is greater than E4 $(10,000)$ arbitrary detector counts from the SEQUEST plus XITANDEM algorithm after selecting the best fit of MS/MS spectra from $2+$ or $3+$ ions and selecting the single best peptide fit for each MS/MS fragmentation set and thus rejecting the redundant correlation of the same MS/MS spectra more than once. a log peptide counts per protein accession; $\mathbf{b} \log _{10}$ peptide counts per gene symbol

from E-3 to E-300 was estimated from the average p-value and number of independent observations (Fig. 4f).

\section{Computation of X!TANDEM at the level of gene symbols}

Genes may be mutated to create new protein sequences [49] RNA may be spliced $[50,51]$ and the proteins may be processed $[52,53]$ leading to different variant forms of related proteins that may sometimes share a similar gene symbol in SQL Server. Selecting the data from the single protein accession with the most peptide correlations per gene symbol is a simple means to summarize the protein results that avoids redundant correlations to peptides shared by homologous proteins. The results of the X!TANDEM algorithm mapped to $~ 19,000$ different gene symbols, open reading frames, or loci with $\sim 14,000$ gene symbols that showed $\geq 5$ independent peptides with greater than E4 intensity and the $\log _{10}$ peptide frequency was normally distributed (Fig. 5a). The mean log peptide intensity per gene symbol ranged over at least 3 orders of magnitude from $\sim \mathrm{E} 8$ to E4 arbitrary counts that approached a Gaussian distribution by quantile plot (Fig. $5 b$ ). The average MS/MS to peptide p-values per gene symbol ranged from E-1 to E-5 (Fig. 5c). Estimating the cumulative protein $\mathrm{p}$-value from the average and the number of observations showed that $\sim 14,000$ gene symbols show a type I error (p-value) and False Discovery Rate (q-value) of 0.001 or lower (Fig. 5d).

\section{Analysis of intensity means and error}

The grand mean $\log _{10}$ precursor intensity of protein gene symbols showed significant differences across the 12 clinical populations versus the ice cold plasma controls values as judged by box plots computed in $\mathrm{R}$ (Fig. 6). Mean $\log _{10}$ precursor intensity showed highly significant variation between the separate disease and control sample treatments by one-way ANOVA ( $p<2$ E-16) (Fig. 6). The results indicate that there was significant variation in the ex vivo cleavage of proteins between the different populations of clinical samples. Global differences in peptide intensity between treatments may confound subsequent comparisons of individual proteins across disease and normal control populations. However, while the grand average intensity was not greatly different between the many treatments, there were some proteins that apparently differed in observation frequency or peptide intensity between normal and disease treatments from different clinical populations versus the ice cold controls. The SQL Server and R software permits the intensity and frequency of any protein to be compared across the clinical treatments with a complete statistical analysis of the linear and Gaussian $\log _{10}$ intensity results. The box plots of cellular proteins that were frequently observed like RAB21 or DENND5A (Fig. 7) seem to indicate there is a significant variation in the $\log _{10}$ mean peptide intensity pattern of cellular proteins cleaved in the disease and matched normal samples from different clinical locations, female samples or samples on ice. For example, large differences were observed across treatments in peptides cleaved ex vivo from transferrin (TTR) and albumin (ALB) between clinical populations or the ice cold controls. 

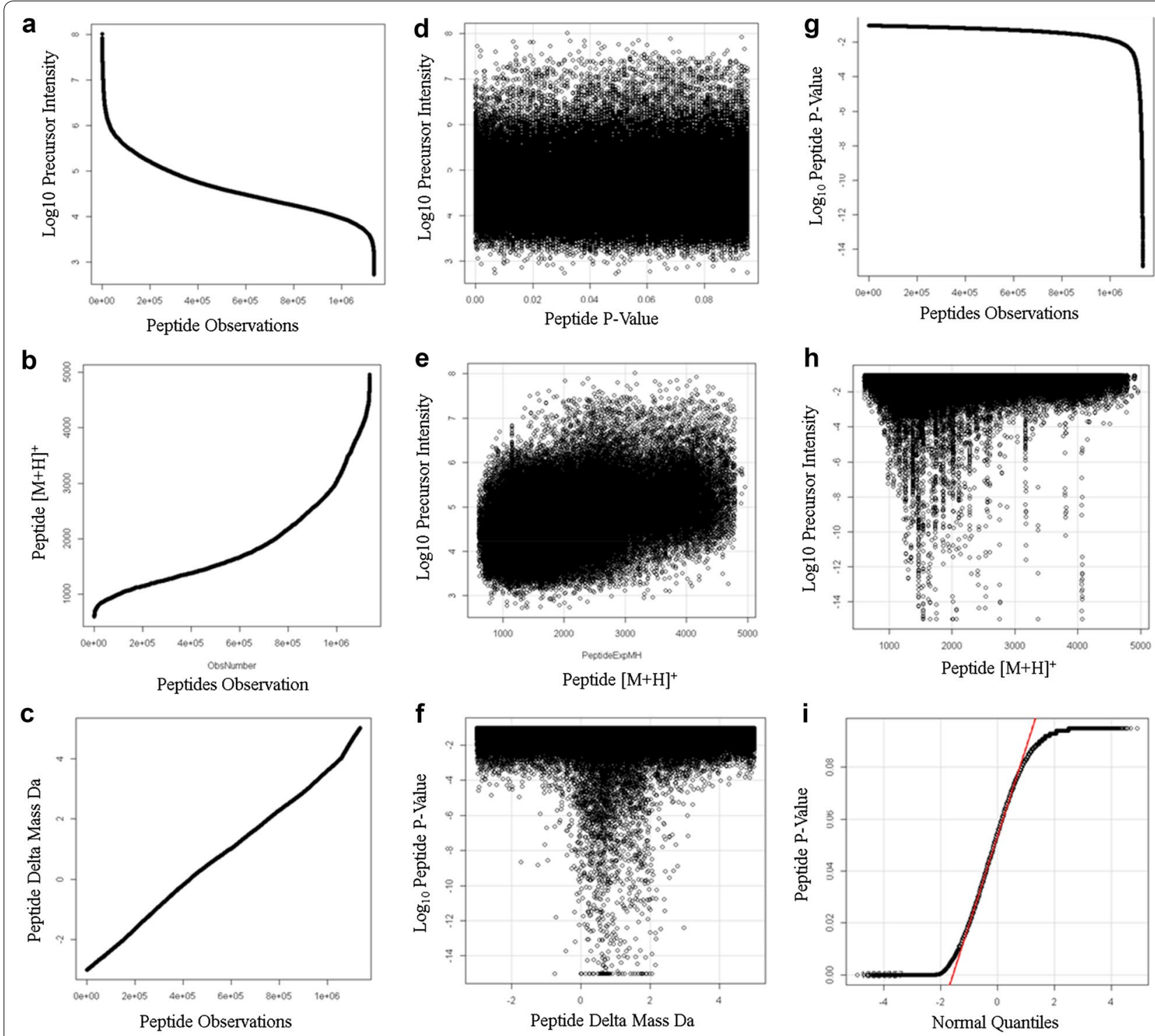

Fig. 3 The distributions of the endogenous Rank 1 tryptic peptides correlated by the XITANDEM algorithm from human EDTA plasma. a The sorted $\log _{10}$ precursor intensity values; $\mathbf{b}$ the sorted peptide $[\mathrm{M}+\mathrm{H}]^{+}$values; $\mathbf{c}$ the sorted peptide delta mass values; $\mathbf{d}$ the scatter plot $\log _{10}$ peptide $p$-values versus precursor intensity; $\log _{10}$ intensity versus peptide $[\mathrm{M}+\mathrm{H}]^{+}$Residual standard error: 0.5488 on 1135580 degrees of freedom Multiple R-squared: 0.2236, Adjusted R-squared: 0.2236 F-statistic: 3.27e + 05 on 1 and 1,135,580 DF, p-value:<2.2e-16); f $\log _{10}$ peptide p-values versus the delta mass value; $\mathbf{g}$, sorted $\log _{10}$ peptide $p$-value; $\mathbf{h} \log _{10}$ peptide $p$-value versus $\left[\mathrm{M}+\mathrm{H}^{+}\right.$; $\mathbf{i}$ quantile plot of peptide $p$-values

\section{STRING analysis}

In a computationally independent method, the distribution of the known protein-protein interactions, cellular location, molecular function and biological processes of the proteins identified from endogenous peptides were computed with respect to a random sampling of the human genome (Table 3). STRING analysis of the top 2000 gene symbols showed a very tight association of mostly cellular proteins that were apparently present in the plasma as protein complexes [54] with related cellular components, molecular functions and biological processes that strongly support the validity of the SEQUEST algorithm after accepting the best charge state and peptide sequence. Examining the top 600 gene symbols clearly indicated there were many protein interactions apparent between the proteins computed (Fig. 8). The peptidome showed statistically significant enrichment of protein interactions (PPI enrichment p-value $\sim 0$ ) and Gene Ontology terms that were consistent with structural and functional relationships between the proteins identified compared to a random sampling of the human genome. The molecular 

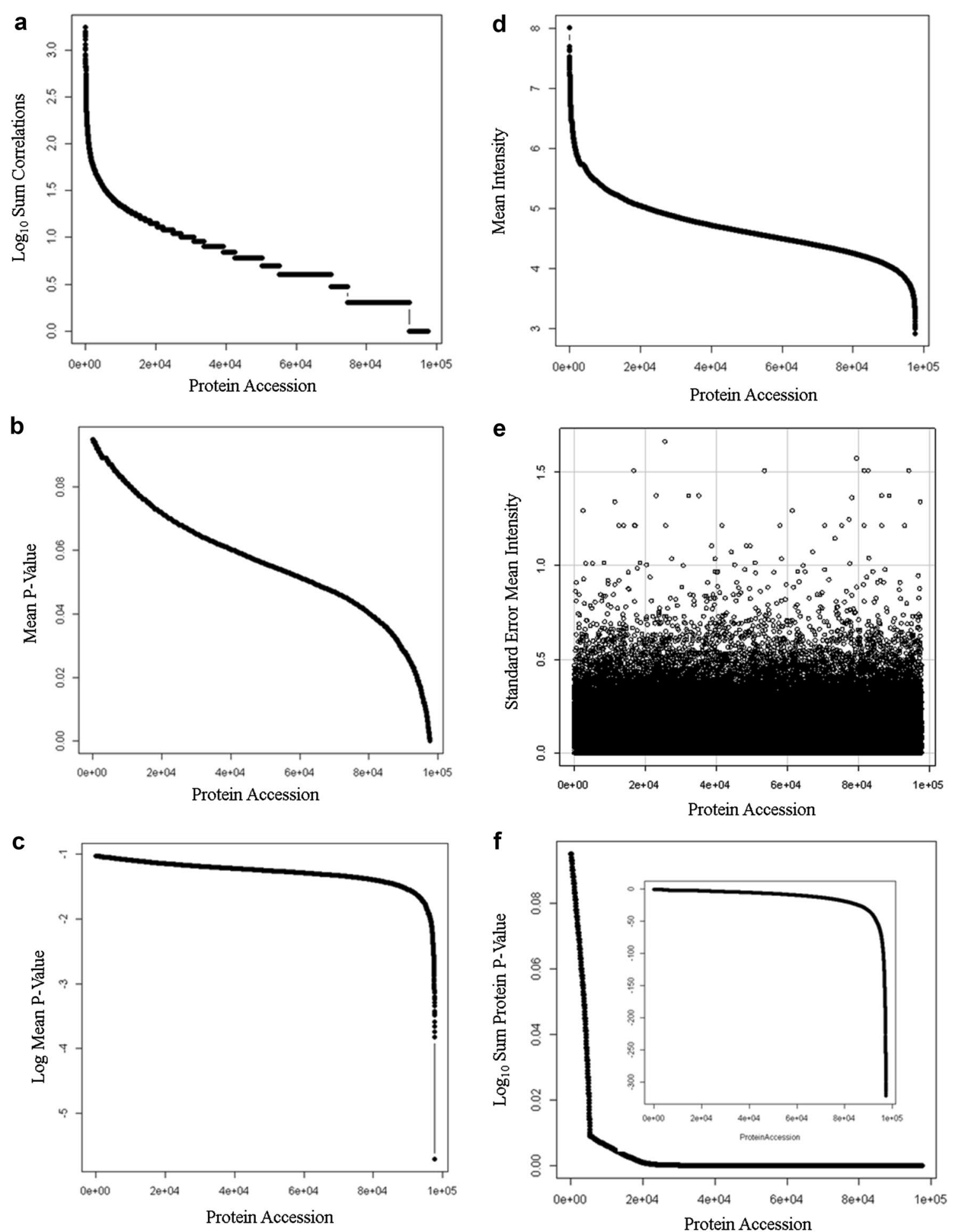

Fig. 4 The distributions of the endogenous Rank 1 tryptic peptides correlated by the X!TANDEM algorithm from human EDTA plasma at the level of protein. $\mathbf{a}$ The peptide to protein accession count; $\mathbf{b}$ the average peptide $p$-value per protein accession; $\mathbf{c}$ the $\log _{10}$ average peptide $p$-value per protein accession; $\mathbf{d} \log _{10}$ precursor intensity value per protein accession; $\mathbf{e}$ the standard error of the protein accession $\log _{10}$ intensity; $\mathbf{f}$ the cumulative $p$-value per protein (inset cumulative $\log _{10} p$-value per protein accession) 

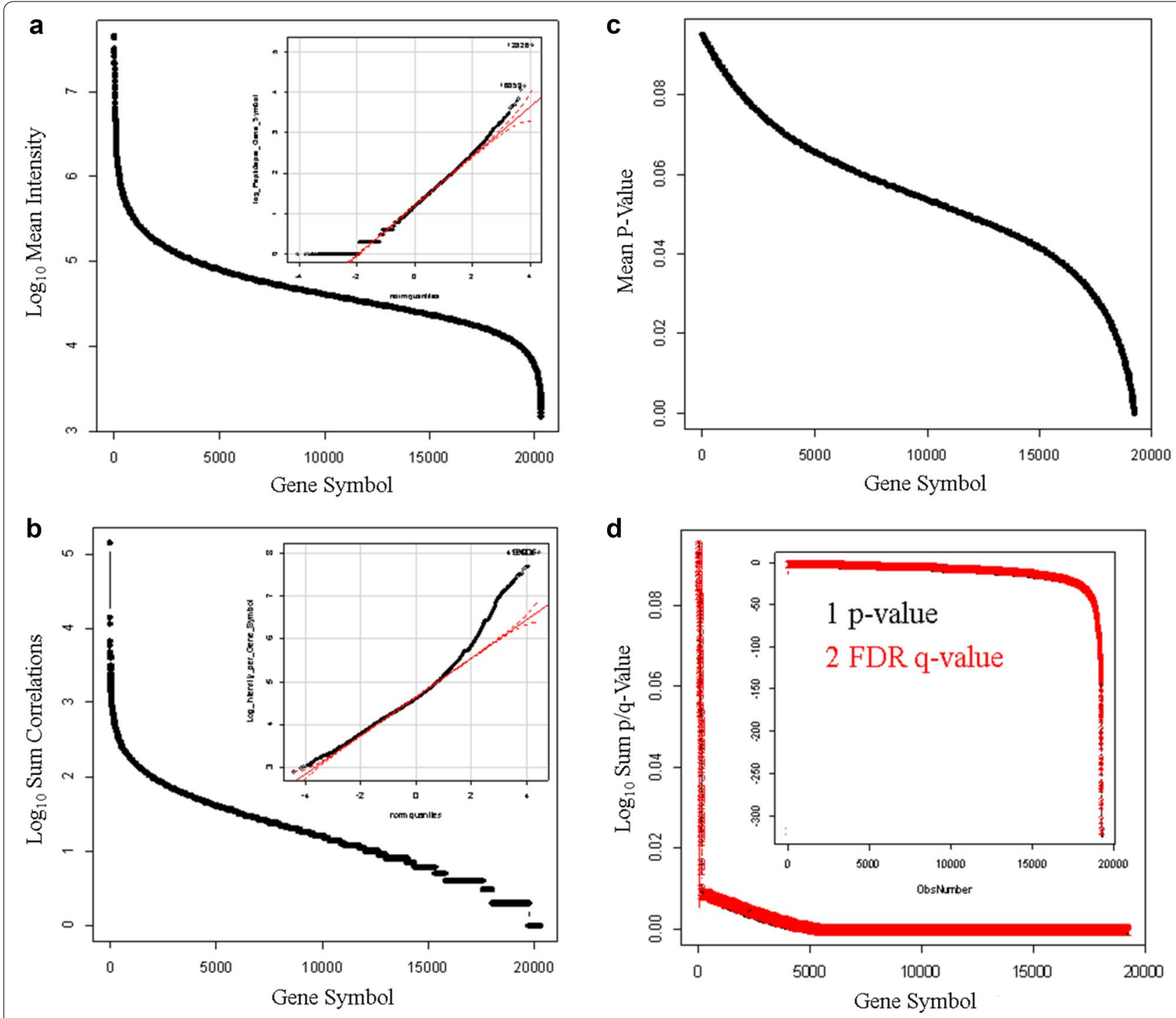

Fig. 5 The distributions of the Rank 1 endogenous tryptic peptides correlated by the X!TANDEM algorithm from human EDTA plasma from the best protein accession per gene symbols. a log peptides observed per gene symbol (inset quantile plot of peptide frequency count); $\mathbf{b}$ log mean precursor intensity per gene symbol (inset quantile plot of $\log _{10}$ intesity); $\mathbf{c} \log$ mean $p$-value per gene symbol; $\mathbf{d}$ cumulative $\log _{10} p$-value per gene symbol (inset $\log _{10}$ cumulative $p$-value per gene symbol)

function of the proteins identified by the best fit peptides showed a significant enrichment in proteins that bind macromolecules such as nucleic acids, other proteins and the extracellular matrix to form supramolecular complexes (Table 3). In agreement with previous results that indicated cellular protein complexes may persist in circulation [54], two of the most commonly observed cellular proteins were RAB21 and DENND5A (DENN/MADD Domain Containing 5A) that is a known RAB binding protein (Fig. 8).

\section{Discussion}

About $\sim 14,000$ (X!TANDEM) to 26,000 (SEQUEST) human proteins (gene symbols, loci and predicted proteins) including many known cellular proteins and protein complexes were confidently detected from the plasma after accepting the distinct, Rank 1 best fit of the MS/MS spectra from the stepwise organic extraction of human EDTA plasma. The large number of proteins detected showed good agreement with previous estimates of the blood proteins by independent methods [14, $18,54]$. 


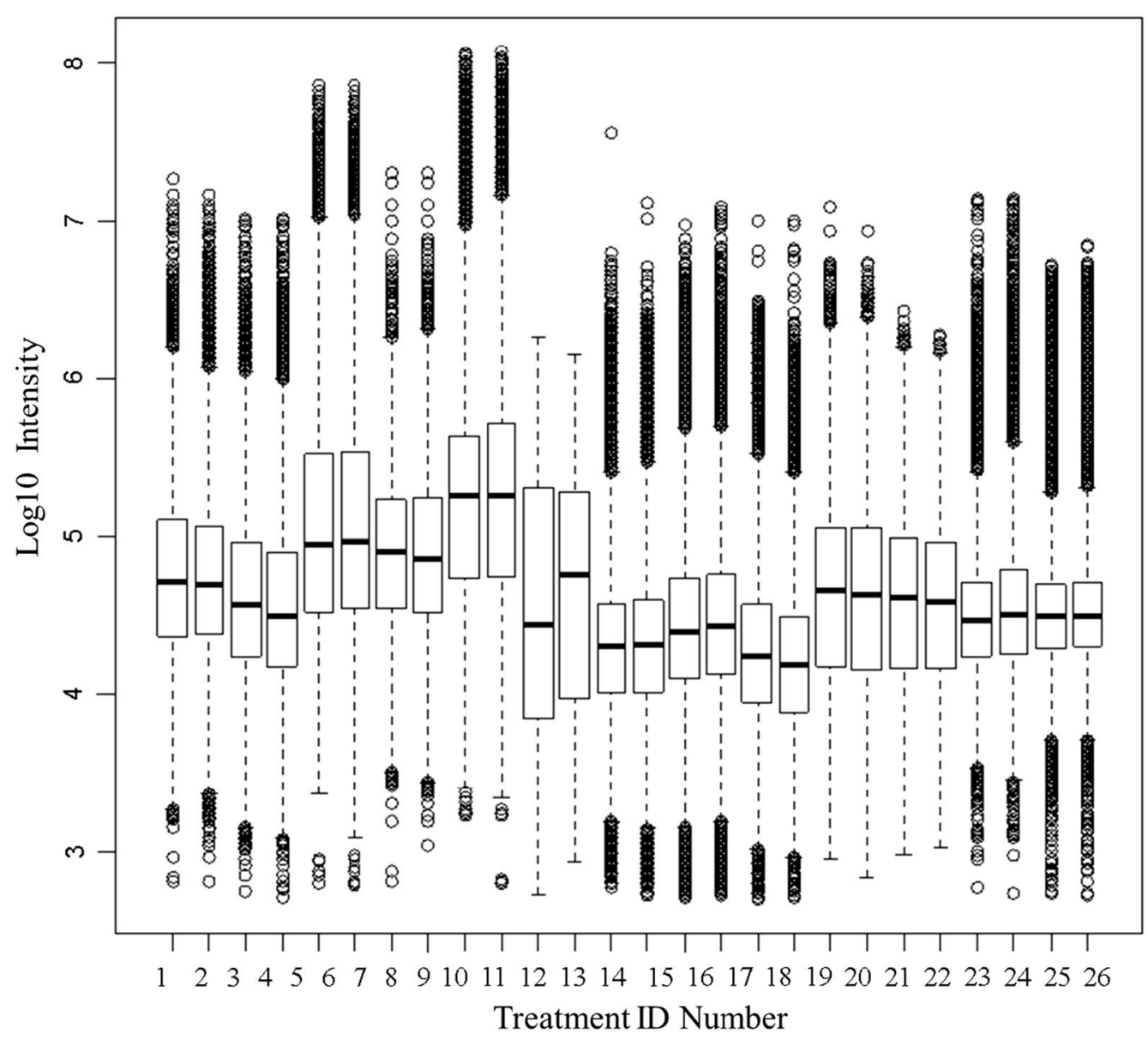

Fig. 6 The box plot and ANOVA of $\log _{10}$ peptide intensity from 26 control and disease EDTA plasma samples. Treatment ID numbers: 1, Alzheimer normal; 2, Alzheimer normal control STYP; 3, AlzHeimer's dementia; 4, Alzheimer's dementia STYP; 5, Cancer_breast; 6, Cancer_breast_STYP; 7, Cancer_control; 8, Cancer_control_STYP; 9, Cancer_ovarian; 10, Cancer_ovarian_STYP; 11, Ice Cold; 12, Ice Cold STYP; 13 , Heart attack Arterial; 14 Heart attack Arterial_STYP; 15, Heart attack normal control, 16, Heart attack normal Control STYP; 17, Heart attack; 18, Heart attack STYP; 19, Multiple Sclerosis normal control; 20, Multiple Sclerosis normal control STYP; Multiple Sclerosis; 22, Multiple Sclerosis STYP, 23 Sepsis; 24, Sepsis STYP; 25, Sepsis normal control; 26, Sepsis normal control STYP. The ANOVA analysis across treatments produced an F Statistic of 13,898 and a p-value of $2 \mathrm{e}-16^{* * *}$ (Additional file 3: Table S3). STYP: serine, threonine, tyrosine phosphorylation

(See figure on next page.)

Fig. 7 The box plot and ANOVA of $\log _{10}$ peptide intensity from 26 control and disease EDTA plasma samples for some frequently observed gene symbols. Treatment ID numbers: 1, Alzheimer normal; 2, Alzheimer normal control STYP; 3, AlzHeimer's dementia; 4, Alzheimer's dementia STYP; 5, Cancer_breast; 6, Cancer_breast_STYP; 7, Cancer_control; 8, Cancer_control_STYP; 9, Cancer_ovarian; 10, Cancer_ovarian_STYP; 11, Ice Cold; 12, Ice Cold STYP; 13, Heart attack Arterial; 14 Heart attack Arterial_STYP; 15, Heart attack normal control, 16, Heart attack normal Control STYP; 17 , Heart attack; 18, Heart attack STYP; 19, Multiple Sclerosis normal control; 20, Multiple Sclerosis normal control STYP; Multiple Sclerosis; 22, Multiple Sclerosis STYP, 23 Sepsis; 24, Sepsis STYP; 25, Sepsis normal control; 26, Sepsis normal control STYP. The ANOVA analysis across treatments produced an F Statistic of 13,898 and a p-value of 2e-16**. STYP: serine, threonine, tyrosine phosphorylation. Note that many proteins were not detected in the ice cold plasma

\section{Discovery of endogenous peptides by organic extraction and LC-ESI-MS/MS}

Exploiting the apparent tendency of circulating proteases to cleave proteins secreted or otherwise released from cells may be a simple strategy to indirectly discover the cellular proteins in human plasma. The random and independent sampling of the endogenous peptides that were extracted by a step gradient of organic/water seems to have identified most human proteins types from EDTA plasma with at least 5 peptides using SEQUEST [55]. 


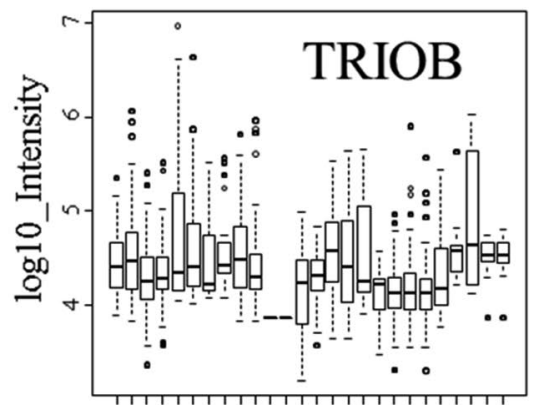

1355791113151719212325

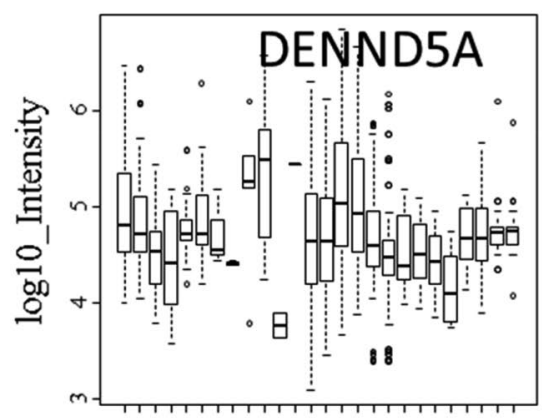

$\begin{array}{lllllll}1 & 3 & 5 & 7 & 9 & 11 & 13151719212325\end{array}$
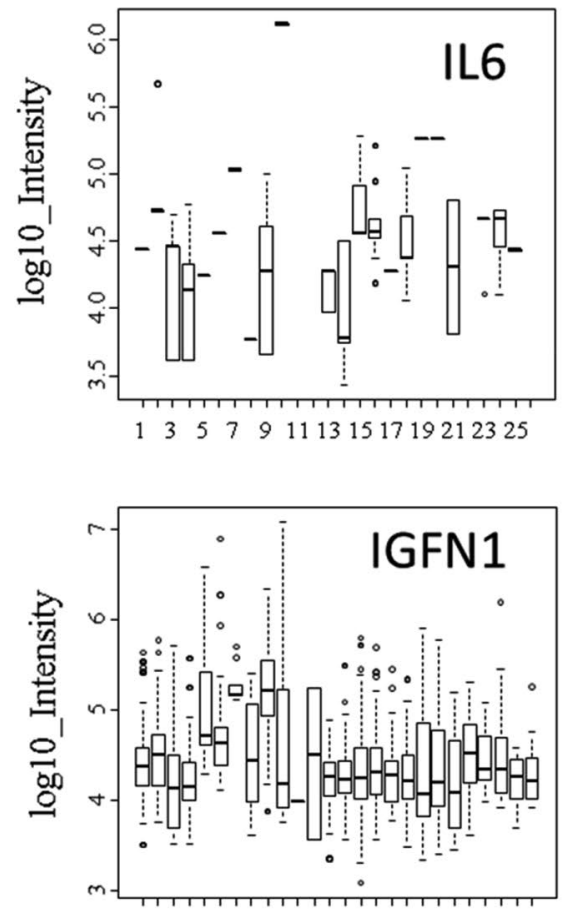

135791113151719212325

Treatment ID

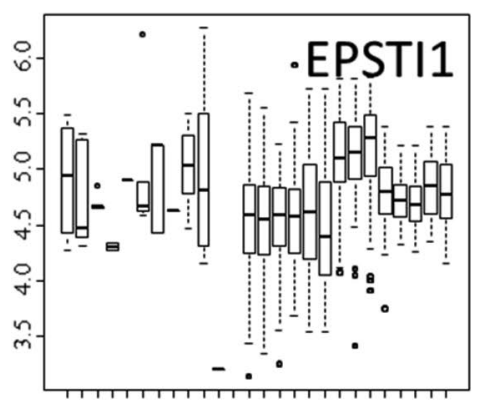

13357991113151719212325

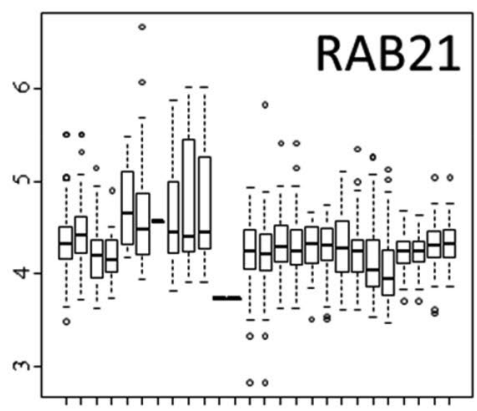

$\begin{array}{lllllll}1 & 3 & 5 & 7 & 9 & 11 & 13151719212325\end{array}$

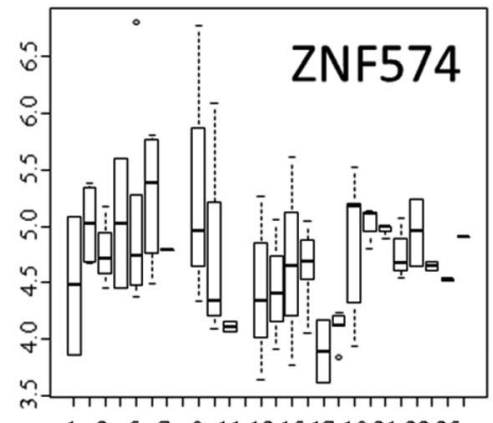

$\begin{array}{lllllll}1 & 3 & 5 & 7 & 9 & 11 & 13151719212325\end{array}$

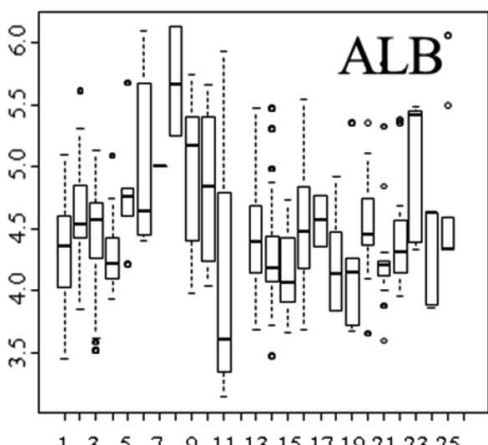

Treatment_ID

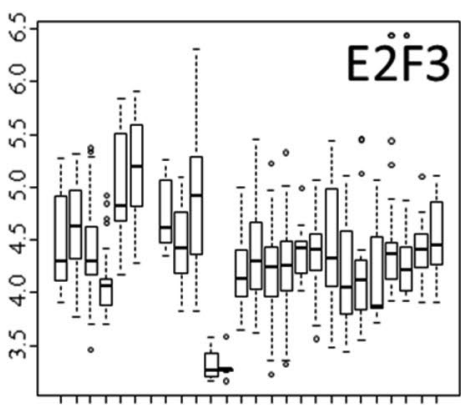

1357991113151719212325

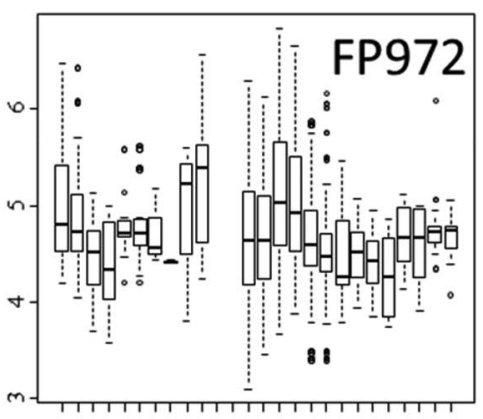

13557991113151719212325

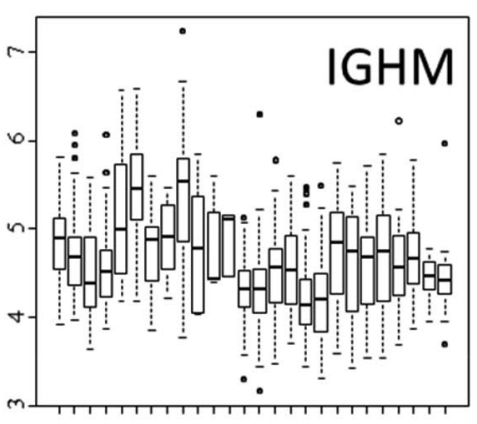

135791113151719212325

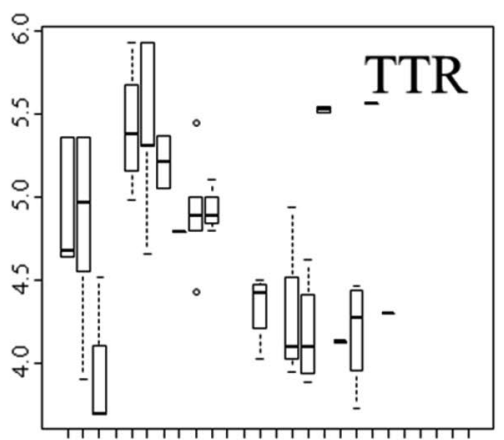

$\begin{array}{lllllll}1 & 3 & 5 & 7 & 9 & 1113151719212325\end{array}$

Treatment_ID
More than $\sim 14,000$ protein gene symbols were detected with at least 5 peptides using the stringent X!TANDEM algorithm [42] that show low computed FDR $(\mathrm{q} \leq 0.0001)$ by the standard statistical method of Benjamini and Hochberg [56] with the generic $\mathrm{R}$ statistical analysis system. 
Table 3 STRING analysis of the molecular function of proteins identified from endogenous tryptic peptides with respect to a random sampling of the human Genome [60]

\begin{tabular}{llcc}
\hline Molecular function (GO) & & & \\
\hline Pathway ID & Pathway description & Count in gene set & False discovery rate \\
\hline GO:0044822 & Poly(A) RNA binding & 64 & $1.18 \mathrm{E}-07$ \\
GO:0003676 & Nucleic acid binding & 135 & $1.77 \mathrm{E}-06$ \\
GO:0003723 & RNA binding & 72 & $2.23 \mathrm{E}-06$ \\
GO:0044877 & Macromolecular complex binding & 55 & $7.04 \mathrm{E}-06$ \\
GO:0005515 & Protein binding & 150 & $3.11 \mathrm{E}-05$ \\
GO:0005198 & Structural molecule activity & 33 & 0.000551 \\
GO:0048407 & Platelet-derived growth factor binding & 5 & 0.00165 \\
GO:0005488 & Binding & 271 & 0.00186 \\
GO:0097159 & Organic cyclic compound binding & 165 & 0.00187 \\
GO:0008092 & Cytoskeletal protein binding & 28 & 0.00433 \\
GO:1901363 & Heterocyclic compound binding & 161 & 0.00433 \\
GO:0032403 & Protein complex binding & 29 & 0.0045 \\
GO:0070742 & C2H2 zinc finger domain binding & 4 & 0.027 \\
GO:0003682 & Chromatin binding & 25 & 0.0276 \\
GO:0005201 & Extracellular matrix structural constituent & 8 & 0.0323
\end{tabular}

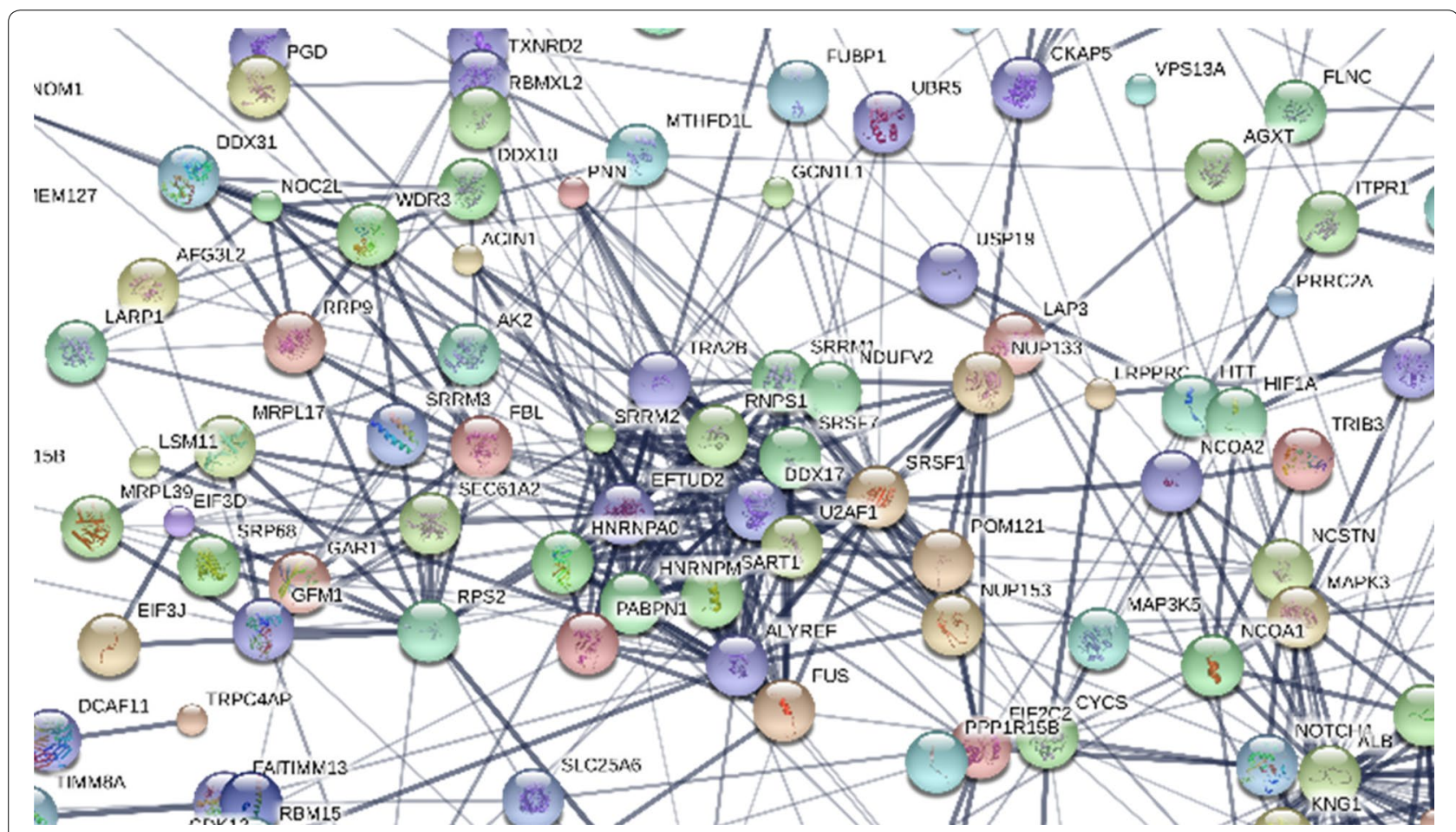

Fig. 8 STRING analysis of the top 2000 gene symbols from the endogenous peptides of normal human plasma. Network Statistics: number of nodes: 478; number of edges: 889; average node degree: 3.72; avg. local clustering coefficient: 0.415; expected number of edges, 654; PPI enrichment $p$-value, $\ll 0.0001$. The image shown was cropped from the entire network for the purpose of graphical clarity 
Random and independent sampling of blood peptides

Random and independent sampling of a population is a standard statistical practice for discovery research. The random sampling of blood peptides from EDTA plasma on separate HPLC columns may be a good practice for discovery of peptides from clinical trials. However, the random and independent sampling of endogenous tryptic peptides generates large amounts of MS/MS data that must be fit, stored, related, filtered, computed, transformed, plotted, and statistically analyzed. The SEQUEST and X!TANDEM algorithms rely on the fit of the MS/MS spectra to the predicted fragments of the human tryptic peptides. The advent of powerful 64-bit PC computing effectively addressed the computational problem that was the limitation on the application of proteomics to compare large populations [57]. The SQL Server/R system may be used to select only the best charge state and peptide sequence for each MS/MS spectra, to compute the cumulative p-value and FDR q-values of the results per gene symbol and provide graphical and statistical analysis. The results of LC-ESI-MS/MS once stored in a generic relational database such as SQL Server may then be statistically analyzed at the level of disease or normal control treatments. The SQL Server and open source R data storage and analysis system provides maximal data size compression, and share simple to use, menu-driven or natural language (Boolean Operator) commands. The random and independent sampling strategy together with analysis in SQL Server/R thus permits the comparison of any peptide or protein across different plasma treatments from multiple institutions.

\section{Sensitivity of LC-ESI-MS/MS for plasma peptides}

In theory all proteins should be detectable in human plasma [58] and in this exhaustive experiment about $\sim 14,000$ human gene symbols, proteins or loci were confidently detected by the X!TANDEM algorithm and about $89 \%$ of all known human proteins were detected by the SEQUEST algorithm. The most commonly detected proteins from endogenous tryptic peptides show good agreement with those from exogenous digestion $[8,14,17,28]$. However, much greater levels of sensitivity for cellular proteins was achieved by the combination of progressive organic extraction together with nanoelectrospray ionization with the linear quadrupole ion trap [41]. The nano LC-ESI-MS/MS system may show sensitivity from micromole to attomole on column [59] and while the instrument is sensitive to any one of these amounts separately it is difficult to identify peptides at widely different concentrations at the same instant. The purpose of the stepwise organic extraction followed by analytical C18 chromatography was to achieve sufficient separation to ensure that low abundance peptides have the opportunity to ionize without competition or suppression from coeluting analytes. For a purified protein the limit of automatic identification by LC-ESI-MS/MS is $\sim 1$ femtomole to 100 attomole on column and so from $0.2 \mathrm{ml}$ of plasma, proteins as low a nanomolar (E-9) and perhaps picomolar (E-12) concentrations may have been detected. Multiple lines of evidence all agree that many, but not all, human proteins were apparently detected and quantified from EDTA plasma by stepwise organic extraction.

\section{Specificity of LC-ESI-MS/MS for plasma peptides}

The protein $\mathrm{p}$-values and FDR corrected q-values computed in $\mathrm{R}$ showed that at least 14,000 proteins were confidently detected in human plasma from precursors of $\geq E 4$ counts that showed low type I error rates in the assignment of molecular identity. The low error rate observed here is consistent with the low error rate of plasma peptides by electrospray compared to random MS/MS and the agreement on plasma proteins from entirely free "no enzyme" computation versus highly constrained fully tryptic peptides $[27,39,40]$.

\section{Selectivity for cellular proteins}

The representation of cellular proteins by endogenous tryptic peptides may reflect the stability of the proteins in blood fluids rather than the concentration of the protein in plasma. The organic extraction method showed a skewed preference for cellular proteins compared to the well-known proteins such as albumin, immunoglobulins, apolipoproteins, protease inhibitors and others that might be more resistant to attack from circulating proteases. The apparent selectivity for cellular proteins is a major advantage for discovery via the low molecular weight peptides of human EDTA plasma. The analysis of the tryptic peptides from selective organic extraction of the acetonitrile-insoluble pellet was an efficient means to enumerate the parent cellular proteins from EDTA plasma. It is not clear if the proteins detected reflect their concentration, susceptibility to cleavage by endoproteases, resistance to turn over by exopeptidase, or the combinations. The observed cellular proteins such as $\mathrm{Zn}$ Finger proteins showed good agreement with the results of protein partition chromatography followed by tryptic digestion $[8,15]$, analysis of peptides by Paul ion trap, and confirmation by Western blot [17].

\section{Confirmation by STRING analysis}

A conceptually and mathematically independent means to confirm the validity of the cellular proteins identified from endogenous tryptic peptides was to search for known structural or functional relationships using the STRING algorithm [60]. If cellular proteins are released into circulation by secretion or exocytosis then 
the protein-protein interactions that existed in the cells might persist to some extent in plasma. The hypothesis that the cellular proteins observed should still show some structural or functional interactions was tested using the STRING algorithm that estimated the probability that the observed protein-protein interaction could occur by random chance approached zero. In agreement with the results of exogenous digestion [54], it appears that proteins circulate as supramolecular complexes and the complex components may proteolytically degrade together in plasma.

\section{Agreement with independent studies}

Immuno depletion, tryptic digestion and ion exchange separation of peptides followed by C18 LC-ESI-MS/MS with "no enzyme" correlation by SEQUEST identified thousands of protein sequences [10-13] from blood from non-tryptic peptides [61] but only a few hundred proteins from high confidence tryptic peptides [62, 63]. Partition chromatography of intact proteins by DEAE resin followed by tryptic digestion and micro spray LC-ESIMS/MS showed at least 600 different types of proteins were identified by high confidence fully tryptic crosscorrelation scores [8] that were independently confirmed [64]. Twelve different partition chromatography columns in parallel, analyzed by the stringent X!TANDEM algorithm showed 4396 proteins from fully tryptic peptides greater than 1,000 counts using micro spray LCESI-MS/MS with a Paul ion trap [15]. Adding up all the proteins discovered from plasma to date from multiple institutions using both SEQUEST and X!TANDEM results in an estimate of about 12,000 proteins but only 3858 of these have three independent peptides $[14,19$, 54]. Multiple groups reported accessions from different databases that hindered comparison between independent experimental groups [65] however a comparison of the proteins sequences using SQL and BLAST with the Chi Square test clearly demonstrated high levels of agreement between groups with respect to random chance [14, $18,54]$. The rigorous X!TANDEM algorithm fits MS/MS spectra within $\pm 0.5 \mathrm{Da}$ and provides a p-value for each MS/MS to peptide fit that may be used to compute the cumulative protein $\mathrm{p}$-value and FDR q-value that should be consistent across experiments. Multiple methods agreed that gene symbols with 3 or more independent best fit peptides of greater than 10,000 intensity counts from a linear quadrupole ion trap with X!TANDEM showed a low type I error rate of protein identification $(\mathrm{p}<0.001)$ [27, 38, 48]. The endogenous tryptic peptides were first identified by MALDI Qq-TOF and LC-ESIMS/MS with an ion trap from $\mathrm{C} 18$ collected peptides [28]. A comparison of blood peptide extraction methods by micro electrospray indicated that precipitating the blood fluid in acetonitrile followed by extraction of the pellet was superior to other methods [19, 37, 47] and identified 510 gene symbols with $\geq 5$ independent peptides. The combination of stepwise organic extraction with micro-electrospray resulted in the identification of 3463 Gene Symbols of which 1880 had $\geq 5$ independent peptides by X!TANDEM ( $\mathrm{p} \leq 0.0001)$. Here the combination of step wise organic extraction of $200 \mu \mathrm{L}$ of plasma with nano electrospray coupled to a linear quadrupole ion trap resulted in the confident identification and quantification of $\sim 14,000$ gene symbols by X!TANDEM that is the largest number of blood proteins identified to date and shows that you can monitor the ex vivo proteolysis of most human proteins, including interleukins, from blood.

\section{Pre-analytical variation}

Collecting samples onto ice might prevent the secretion of proteins from blood cells, and prevent the degradation of dissolved proteins by proteases, that may occur ex vivo. The effect of ex vivo proteolysis on the observed endogenous peptides of blood samples is known to be large from the use of acid quench, protease inhibitors or ice to preserve the sample $[27-29,47]$. We previously showed that plasma from blood collected into EDTA tubes on ice is stable when freeze dried with low peptide frequency and intensity but starts to degrade when dissolved at room temperature [27, 29, 47]. The frequency and/or intensity of peptide or protein observations increased in samples incubated at room temperature compared to ice cold samples and the two pools shared some peptides and proteins [16, 27, 28, 38, 47]. Differences in the frequency of observation and average precursor intensity values of specific cellular proteins like RAB1 or DENDD5A across the clinical samples compared to the ice cold controls indicates the at least some of the peptides and or proteins observed have been released from cells, or degraded by proteases released or activated, ex vivo. The approach of random and independent sampling of tryptic peptides from defined populations using LC-ESI-MS/MS and classical statistics may have some clinical utility: There was apparently statistically significant variation in the cleavage of endogenous peptides from cellular proteins across the different disease and normal treatments, female samples and ice cold controls.

\section{Conclusion}

Multiple independent best fit peptide correlations, low FDR q-values per gene symbol, partition of variation over peptides and proteins, and significant STRING analysis all agreed that most human proteins were identified in EDTA plasma by stepwise organic fractionation, followed by random and independent sampling of the endogenous tryptic peptides by nano LC-ESI-MS/MS fit by the 
rigorous X!TANDEM algorithm. The use of a stepwise organic solvent gradient for the selective extraction of tryptic peptides into 10 discrete fractions followed by collection and analysis by $\mathrm{C} 18$ reversed phase [27] showed high peptide intensity and signal to noise ratios, resulting in LC-ESI-MS/MS correlations to endogenous tryptic peptides from apparently low abundance cellular proteins in blood plasma. The large amounts of raw and calculated data from thousands of LC-ESI-MS/MS experiments from multiple clinical centers can be efficiently stored and related in SQL SERVER and statistically analyzed using the open source R statistical system. It was apparently possible to fractionate the blood fluids using differential solubility in an organic step gradient [38] together with nanospray LC-ESI-MS/MS to make a comprehensive discovery of the endogenous tryptic peptides and phospho peptides from almost all human proteins from EDTA blood plasma. Many of the proteins observed were either secreted from cells, and/or degraded by proteases that were released or activated ex vivo. The detection of the endogenous tryptic peptides may reflect the concentration of the parent protein and/or the stability of the parent proteins in the presence of circulating proteases and/or peptidases in the EDTA plasma. The method was appropriate for discovery of variation in endogenous plasma peptides from cellular proteins that showed significant differences in observation frequency and/or average intensity across the disease and control plasma treatments.

\section{Additional files}

Additional file 1. Supplemental Table I. The tryptic peptidome of human EDTA plasma.

Additional file 2. Supplemental Table II. The interleukins, growth factors, cytokines, chemokines and necrosis factors of human EDTA plasma.

Additional file 3: Table S3. ANOVA and Tukey Kramer HSD test.

\section{Authors' contributions}

JD, TT, ZZC, MT: prepared samples and performed LC-ESI-MS/MS analysis; $\mathrm{PB}$, performed SEQUEST and XITANDEM correlation and parsed the results into an SQL Server database; AFM, prepared samples, performed LC-ESI-MS/ MS analysis, and proofed the manuscript:; TN, MTH, MP, NM performed LC-ESI-MS/MS analysis; AR, planned the study and collected heart attack samples; ES, planned the study and collected heart attack samples; ASS, EPD, KWMS: planned the study and wrote a grant in support of the study; CCS, JCM: planned the study and collected sepsis samples; AR, planned the study, collected sepsis samples, and devised the peptide collection and sample injection method; CA, SM: planned the study and collected cancer samples; $\mathrm{DH}$, planned the study and collected sepsis; PS, planned the study and collected Alzheimer's dementia samples; JK, planned the study and collected multiple sclerosis samples; $C T$, planned the study, collected multiple sclerosis and Alzheimer's samples and helped write the study; JGM, planned the study, wrote grants in support of the study, performed the R statistical analysis and wrote the manuscript. All authors read and approved the final manuscript.

\section{Author details}

${ }^{1}$ Ryerson Analytical Biochemistry Laboratory (RABL), Department of Chemistry and Biology, Faculty of Science, Ryerson University, 350 Victoria St, Toronto, ON, Canada. ${ }^{2}$ Institute of Cardiovascular Sciences, St Boniface Hospital Research Center, University of Manitoba, Winnipeg, Canada. ${ }^{3}$ Division of Cardiology, Department of Medicine, McMaster University, Hamilton, Canada. ${ }^{4}$ St. Michael's Hospital, Keenan Chair in Medicine, University of Toronto, Toronto, Canada. ${ }^{5}$ St. Michael's Hospital, Keenan Research Centre for Biomedical Science, Toronto, Canada. ${ }^{6}$ Program for Cancer Therapeutics, Ottawa Hospital Research Institute, Ottawa, Canada. ${ }^{7}$ Clinical Evaluation Research Unit, Kingston General Hospital, Kingston, Canada. ${ }^{8}$ Alzheimer Center, Department of Neurology, Amsterdam University Medical Centers, Vrije Universiteit, Amsterdam Neuroscience, Amsterdam, The Netherlands. ${ }^{9}$ MS Center, Department of Neurology, Amsterdam University Medical Centers, Vrije Universiteit, Amsterdam Neuroscience, Amsterdam, The Netherlands. ${ }^{10}$ Neurochemistry Lab and Biobank, Department of Clinical Chemistry, Amsterdam University Medical Centers, Vrije Universiteit, Amsterdam Neuroscience, Amsterdam, The Netherlands. ${ }^{11}$ Mount Sinai Hospital Research Institute, University of Toronto, Toronto, Canada. ${ }^{12}$ University of Windsor, Windsor, Canada. ${ }^{13}$ International Biobank of Luxembourg (IBBL), Luxembourg Institute of Health (formerly CRP Sante Luxembourg), Strassen, Luxembourg.

\section{Acknowledgements}

We thank Dr. R.A. Phillips for his long running support for this program of research, his aid in obtaining human EDTA plasma from the Ontario Tumor Bank, which is funded by the Ontario Institute for Cancer Research, and his help and opinions in the preparation of the manuscript.

\section{Competing interests}

The authors declare that they have no competing interests.

Availability of data and materials

The raw data is large and must be shipped by hard drive.

Consent for publication

No original figures or tables from any other publication was reproduced in this publication.

\section{Ethics approval and consent to participate}

Human EDTA plasma samples were obtained under Ryerson Ethical Reviews Board Protocol REB 2015-207.

\section{Funding}

Funding to develop the SQL SERVER - R computation platform, and to sample the breast and ovarian cancer samples, provided by the Ontario Institute of Cancer Research through the Ontario Cancer Biomarker Network to KWS, EPD, and JGM. The funding to create the reference control samples and sample the $\mathrm{AD}$ and MS plasma and controls was from Fonds National de la Recherche, through Luxembourg Institute of Health LIH (formerly CRP Sante) and the Integrated Biobank of Luxembourg (IBBL) to JGM. The heat attack results were collected using funding from the Heart and Stroke Foundation of Ontario and Canada to JGM. Funding for wet lab and LC-ESI-MS/MS instruments and for sampling Sepsis was from the Natural Science and Engineering Research Council of Canada (NSERC) for the CRD Grant with YYZ Pharmatech to JGM.

\section{Publisher's Note}

Springer Nature remains neutral with regard to jurisdictional claims in published maps and institutional affiliations.

Received: 24 August 2018 Accepted: 23 October 2018

Published online: 01 December 2018

\section{References}

1. Putnam F. The plasma proteins: structure function, and genetic control. 2nd ed. New York: Academic Press; 1975.

2. Burtis CA, Ashwood ER, DE Bruns, editors. Tietz fundamentals of clinical chemistry. PPiladelphia: Saunders; 2001. p. 1091. 
3. Welinder KG. Generation of peptides suitable for sequence analysis by proteolytic cleavage in reversed-phase high-performance liquid chromatography solvents. Anal Biochem. 1988;174(1):54-64

4. Fenn JB, et al. Electrospray ionization for mass spectrometry of large biomolecules. Science. 1989;246(4926):64-71.

5. Hunt DF, et al. Protein sequencing by tandem mass spectrometry. Proc Natl Acad Sci USA. 1986;83(17):6233-7.

6. Yates JR 3rd, et al. Method to correlate tandem mass spectra of modified peptides to amino acid sequences in the protein database. Anal Chem. 1995;67(8):1426-36

7. Link AJ, et al. Direct analysis of protein complexes using mass spectrometry. Nat Biotechnol. 1999;17(7):676-82.

8. Marshall J, et al. Human serum proteins preseparated by electrophoresis or chromatography followed by tandem mass spectrometry. J Proteome Res. 2004;3(3):364-82.

9. Anderson NL, Anderson NG. A two-dimensional gel database of human plasma proteins. Electrophoresis. 1991;12(11):883-906.

10. Adkins JN, et al. Toward a human blood serum proteome: analysis by multidimensional separation coupled with mass spectrometry. Mol Cell Proteomics. 2002;1(12):947-55.

11. Tirumalai RS, et al. Characterization of the low molecular weight human serum proteome. Mol Cell Proteomics. 2003;2(10):1096-103.

12. Shen Y, et al. Ultra-high-efficiency strong cation exchange LC/RPLC/ MS/MS for high dynamic range characterization of the human plasma proteome. Anal Chem. 2004;76(4):1134-44.

13. Shen $Y$, et al. Characterization of the human blood plasma proteome. Proteomics. 2005;5(15):4034-45.

14. Bowden P, et al. Meta sequence analysis of human blood peptides and their parent proteins. J Proteomics. 2010;73:1163-75.

15. Tucholska M, et al. Human serum proteins fractionated by preparative partition chromatography prior to LC-ESI-MS/MS. J Proteome Res. 2009;8:1143-55.

16. Dufresne J, et al. The proteins cleaved by endogenous tryptic proteases in normal EDTA plasma by C18 collection of peptides for liquid chromatography micro electrospray ionization and tandem mass spectrometry. Clin Proteomics. 2017;14:39.

17. Tucholska M, et al. The endogenous peptides of normal human serum extracted from the acetonitrile-insoluble precipitate using modified aqueous buffer with analysis by LC-ESI-Paul ion trap and Qq-TOF. J Proteomics. 2010;73(6):1254-69.

18. Bowden P, Beavis R, Marshall J. Tandem mass spectrometry of human tryptic blood peptides calculated by a statistical algorithm and captured by a relational database with exploration by a general statistical analysis system. J Proteomics. 2009;73:103-11.

19. Zhu $P$, et al. Comparison of protein expression lists from mass spectrometry of human blood fluids using exact peptide sequences versus BLAST. Clin Proteomics. 2007:2(3-4):185-203.

20. Zhu P, et al. Chi square comparison of tryptic peptide-to-protein distributions of tandem mass spectrometry from blood with those of random expectation. Anal Biochem. 2011;409(2):189-94.

21. Zhu P, et al. Peptide-to-protein distribution versus a competition for significance to estimate error rate in blood protein identification. Anal Biochem. 2011:411:241-53.

22. Zolg DP, et al. Building ProteomeTools based on a complete synthetic human proteome. Nat Methods. 2017;14(3):259-62.

23. Chelius $D$, et al. Analysis of the adenovirus type 5 proteome by liquid chromatography and tandem mass spectrometry methods. J Proteome Res. 2002:1(6):501-13.

24. Szczeklik A. Trypsin-like activity of serum: its origin and electrophoretic separation. Clin Chim Acta. 1969:23(1):219-29.

25. Ivanov VT, Yatskin ON. Peptidomics: a logical sequel to proteomics. Expert Rev Proteomics. 2005;2(4):463-73.

26. Yatskin $\mathrm{ON}$, et al. Isolation of peptides from rat tissues: peptidomics vs degradomics. Adv Exp Med Biol. 2009;611:399-400.

27. Dufresne J, et al. Random and independent sampling of endogenous tryptic peptides from normal human EDTA plasma by liquid chromatography micro electrospray ionization and tandem mass spectrometry. Clin Proteomics. 2017:14:41

28. Marshall J, et al. Processing of serum proteins underlies the mass spectral fingerprinting of myocardial infarction. J Proteome Res. 2003;2:361-72.
29. Dufresne J, et al. Freeze-dried plasma proteins are stable at room temperature for at least 1 year. Clin Proteomics. 2017;14:35.

30. Mahboob S, et al. Is isolation of comprehensive human plasma peptidomes an achievable quest? J Proteomics. 2015;127(Pt B):300-9.

31. Richter $\mathrm{R}$, et al. Composition of the peptide fraction in human blood plasma: database of circulating human peptides. J Chromatogr B Biomed Sci Appl. 1999;726(1-2):25-35.

32. Oleschuk RD, et al. Characterization of plasma proteins adsorbed onto biomaterials. By MALDI-TOFMS. Biomaterials. 2000;21(16):1701-10.

33. Petricoin $\mathrm{EF}$, et al. Use of proteomic patterns in serum to identify ovarian cancer. Lancet. 2002;359(9306):572-7.

34. Chertov $\mathrm{O}$, et al. Organic solvent extraction of proteins and peptides from serum as an effective sample preparation for detection and identification of biomarkers by mass spectrometry. Proteomics. 2004;4(4):1195-203.

35. Zhou $M$, et al. An investigation into the human serum "interactome". Electrophoresis. 2004;25(9):1289-98.

36. Tucholska $M$, et al. Endogenous peptides from biophysical and biochemical fractionation of serum analyzed by matrix-assisted laser desorption/ ionization and electrospray ionization hybrid quadrupole time-of-flight. Anal Biochem. 2007:370:228-45.

37. Declan Williams PZ, Bowden P, Stacey C, McDonell M, Kowalski P, Kowalski JM, Evans K, Diamandis EP, Michael Siu KW, Marshall J. Comparison of methods to examine the endogenous peptides of fetal calf serum clinical proteomics. Clin Proteomics. 2007;2(1):67-89.

38. Dufresne J, et al. A method for the extraction of the endogenous tryptic peptides (peptidome) from human EDTA plasma. Anal Biochem. 2018:549:188-96

39. Bowden P, et al. Quantitative statistical analysis of standard and human blood proteins from liquid chromatography, electrospray ionization, and tandem mass spectrometry. J Proteome Res. 2012;11:2032-47.

40. Florentinus $A K$, et al. Identification and quantification of peptides and proteins secreted from prostate epithelial cells by unbiased liquid chromatography tandem mass spectrometry using goodness of fit and analysis of variance. J Proteomics. 2012;75:1303-17.

41. Schwartz JC, Senko MW, Syka JE. A two-dimensional quadrupole ion trap mass spectrometer. J Am Soc Mass Spectrom. 2002;13(6):659-69.

42. Craig R, Beavis RC. TANDEM: matching proteins with tandem mass spectra. Bioinformatics. 2004;20(9):1466-7.

43. Howard JC, et al. OxLDL receptor chromatography from live human U937 cells identifies SYK(L) that regulates phagocytosis of oxLDL. Anal Biochem. 2016:513:7-20.

44. Florentinus AK, et al. The Fc receptor-cytoskeleton complex from human neutrophils. J Proteomics. 2011;75:450-68.

45. Eckel-Passow JE, et al. An insight into high-resolution mass-spectrometry data. Biostatistics. 2009;10(3):481-500.

46. Krokhin OV, Ens W, Standing KG. MALDI QqTOF MS combined with off-line HPLC for characterization of protein primary structure and posttranslational modifications. J Biomol Tech. 2005;16(4):429-40.

47. Williams $D$, et al. Precipitation and selective extraction of human serum endogenous peptides with analysis by quadrupole time-of-flight mass spectrometry reveals posttranslational modifications and low-abundance peptides. Anal Bioanal Chem. 2010;396:1223-47.

48. Dufresne $J$, et al. Re-evaluation of the rabbit myosin protein standard used to create the empirical statistical model for decoy library searching. Anal Biochem. 2018:560:39-49.

49. Melo JV. The molecular biology of chronic myeloid leukaemia. Leukemia. 1996;10(5):751-6.

50. Cech TR, Zaug AJ, Grabowski PJ. In vitro splicing of the ribosomal RNA precursor of Tetrahymena: involvement of a guanosine nucleotide in the excision of the intervening sequence. Cell. 1981:27(3 Pt 2):487-96.

51. Sharp PA. The discovery of split genes and RNA splicing. Trends Biochem Sci. 2005;30(6):279-81.

52. Addo $L$, et al. The three isoforms of hepcidin in human serum and their processing determined by liquid chromatography-tandem mass spectrometry (LC-tandem MS). Int J Hematol. 2016;103(1):34-43.

53. Zhen EY, et al. Circulating FGF21 proteolytic processing mediated by fibroblast activation protein. Biochem J. 2016;473(5):605-14.

54. Marshall J, et al. Creation of a federated database of blood proteins: a powerful new tool for finding and characterizing biomarkers in serum. Clin Proteomics. 2014;11(1):3. 
55. Cargile BJ, Bundy JL, Stephenson JL Jr. Potential for false positive identifications from large databases through tandem mass spectrometry. J Proteome Res. 2004;3(5):1082-5.

56. Benjamini $Y$, Hochberg Y. Controlling false discovery rate: a practical approach to multiple testing. J R Stat Soc. 1995;57(1):289-300.

57. Patterson SD. Data analysis-the Achilles heel of proteomics. Nat Biotechnol. 2003;21(3):221-2.

58. Anderson NL, Anderson NG. The human plasma proteome: history, character, and diagnostic prospects. Mol Cell Proteomics. 2002;1(11):845-67.

59. Onisko B, et al. Mass spectrometric detection of attomole amounts of the prion protein by nanoLC/MS/MS. J Am Soc Mass Spectrom. 2007;18(6):1070-9.

60. von Mering C, et al. STRING: known and predicted protein-protein associations, integrated and transferred across organisms. Nucl Acids Res. 2005;33(Database issue):D433-7.
61. Olsen JV, Ong SE, Mann M. Trypsin cleaves exclusively C-terminal to arginine and lysine residues. Mol Cell Proteomics. 2004;3(6):608-14.

62. Cominetti $\mathrm{O}$, et al. Proteomic biomarker discovery in 1000 human plasma samples with mass spectrometry. J Proteome Res. 2016;15(2):389-99.

63. Whiteaker JR, et al. Head-to-head comparison of serum fractionation techniques. J Proteome Res. 2007;6(2):828-36.

64. Schenk S, et al. A high confidence, manually validated human blood plasma protein reference set. BMC Med Genomics. 2008;1:41.

65. Anderson NL, et al. The human plasma proteome: a nonredundant list developed by combination of four separate sources. Mol Cell Proteomics. 2004;3(4):311-26.
Ready to submit your research? Choose BMC and benefit from:

- fast, convenient online submission

- thorough peer review by experienced researchers in your field

- rapid publication on acceptance

- support for research data, including large and complex data types

- gold Open Access which fosters wider collaboration and increased citations

- maximum visibility for your research: over $100 \mathrm{M}$ website views per year

At BMC, research is always in progress.

Learn more biomedcentral.com/submissions 